\title{
Occurrence of Different Types of Endometrial Carcinoma in Hysterectomy Specimens from Different Hospitals in Karachi, Pakistan
}

\author{
Izhar Fatima ${ }^{1}$, Muhammad Noman Rashid ${ }^{2,}$, Farha Ahmed $^{3}$, Ali Muhammad Soomro ${ }^{4}$ \\ ${ }^{1}$ Department of Pathology, Shaheed Mohtarma Benazir Bhutto Medical College, Karachi, Pakistan \\ ${ }^{2}$ Department of Physiology, Shaheed Mohtarma Benazir Bhutto Medical College, Karachi, Pakistan \\ ${ }^{3}$ Department Community Health Sciences, Ziauddin University, Karachi, Pakistan \\ ${ }^{4}$ Department of Physiology, University of Sindh, Jamshoro, Sindh, Pakistan
}

Email address:

dr.nomanrashid@yahoo.com (M. N. Rashid)

\section{To cite this article:}

Izhar Fatima, Muhammad Noman Rashid, Farha Ahmed, Ali Muhammad Soomro. Occurrence of Different Types of Endometrial Carcinoma in Hysterectomy Specimens from Different Hospitals in Karachi, Pakistan. American Journal of Life Sciences.

Vol. 3, No. 3, 2015, pp. 143-146. doi: 10.11648/j.ajls.20150303.13

\begin{abstract}
Introduction: Endometrial carcinoma can occur due to different causes. It is associated with other diseases like endometrial hyperplasia, obesity, diabetes, early menarche and late menopause. Histological and histochemical procedures, help in diagnosis of different types of endometrial carcinoma. Objectives: To identify predominant histological and histochemical type of endometrial carcinoma from hysterectomy specimens collected from different tertiary care hospitals of Karachi, Pakistan. Methodology: Slides / paraffin blocks of endometrial biopsies of hysterectomy specimens were taken, from $1^{\text {st }}$ January 2008 to $31^{\text {st }}$ December 2012. Results: In present study, total 226 hysterectomy cases were received in which 70 $(30.97 \%)$ cases of different type of endometrial carcinoma were studied. The maximum 46 (65.71\%) cases were of endometroid secretory adenocarcinoma. 16 (22.90\%) cases, of Endometroid pappilary carcinoma. 3 (4.30\%) cases of ciliated adenocarcinoma and $1(1.42 \%)$ case villoglandular endometrial cancer. Conclusion: Increased tendency of endometroid secretory adenocarcinoma of endometrium as $46(65.71 \%)$ cases out of 70 cases.
\end{abstract}

Keywords: Endometrial, Clear Cell, Endometroid, Mixed Type Carcinoma, Mucinous Adenocarcinoma, Serous Adenocarcinoma, Signet Ring Cell Carcinoma

\section{Introduction}

Endometrial carcinoma is common in developed, industrialized countries, and appears as a seventh most common tumor in the world.[1,2] About $6 \%$ of new female cases and $3 \%$ of female cancer deaths are occurred per year.[3] Chronic or long standing hyperplastic endometrium may transform in endometrial carcinoma.[4] In a study $22 \%$ patient with atypical hyperplasia, developed cancer.[5] Breast cancer, ovarian cancer, anovulatory cycles, age over 35, lack of exercise [6] and heavy daily alcohol intake are also the risk factors of endometrial carcinoma.[7] The causes of endometrial carcinoma are endometrial hyperplasia, unopposed estrogen therapy, obesity, diabetes, early menarche, late menopause, postmenopausal bleeding and progesterone therapy.[8] The carcinoma is three times more common in diabetic women then non diabetic.[9] High intake of animal (saturated) fat may increase the risk of endometrial cancer, while vegetables and fruits may do the opposite. Increased endogenous estrogen exposures are associated with the increase risk of endometrial cancer e.g. early menarche, late menopause (2.4-fold), nulliparity (2-fold), the polycystic ovarian syndrome, diabetes mellitus (2.8-fold), high blood pressure (1.5-fold), obesity (up to 10-fold) and tumors with estrogen production, atypical endometrial hyperplasia (10fold). Exogenous risk factors of endometrial carcinoma are previous irradiation of the pelvis, estrogen replacement therapy (unopposed HRT) and tamoxifen therapy cause 6.4fold increase. Prolonged intake of synthetic estrogens is associated with 15 fold higher incidence of endometrial carcinoma, while $35 \%$ patients with endometrial carcinoma have no signs of obesity or hyperestrogenism.[10]

There are several different histological subtypes of endometrial carcinoma, which are classified into two major 
groups. The type I or estrogen-dependent cancers are the low-grade endometroid tumors, with good prognosis. While the less common type II or non-estrogen-dependent cancers are high-grade malignant tumors like serous papillary, clear cell and adenosquamous carcinomas having poor prognosis and occur in older or perimenopausal women.[11] Welldifferentiated Endometroid adenocarcinoma can originate from endometrial hyperplasia. It is differentiated from atypical hyperplasia by the finding of clear stromal invasion, or "back-to-back" glandular proliferation. Myometrial infiltration can occur.[12] Estrogen related adenocarcinomas occurring in younger and perimenopausal women, are well differentiated carcinomas, originating from atypical endometrial hyperplasia. These are low grade tumors, with long history, less myometrial invasion, rare lymphatic spread and included in $1^{\text {st }}$ category.[13,14] Serous adenocarcinoma and clear cell carcinomas are commonly associated with an atrophic endometrium. Endometrial intraepithelial carcinoma may transform in serous carcinoma and possibly of some clear cell carcinomas.[14]. These tumors are, higher grade malignant tumors, with shorter history, deeper myometrial invasion, more lymphatic metastasis and poor prognosis, included in $2^{\text {nd }}$ category. [13].

After extensive international and national literature search it was found that most predominant carcinoma in age groups that are premenopausal or post-menopausal was papillary/ ciliated carcinoma. The aim of the study is to identify the predominant carcinoma in above mentioned age groups in patients of Karachi, Pakistan.

\section{Material and Methods}

Total 226 Slides / paraffin blocks of endometrial biopsies from patients 34 to 67 years of age were studied from $1^{\text {st }}$ January 2008 to $31^{\text {st }}$ December 2011, retrospectively and from $1^{\text {st }}$ January 2012 to $31^{\text {st }}$ December 2012, prospectively. The biopsies were received from tertiary care hospitals of Karachi.

A clinical protocol including the particulars about the patients name, age, and diagnosis were obtained from the surgical pathology registers, request cards and copies of the reports. Haemotoxylin and eosin (H\&E) stained slides of all cases were used with special staining help in reaching a specific diagnosis.

\section{Results}

In the present study, total 226 hysterectomy cases of different type of diseases were studied including $70(31 \%)$ cases of endometrial carcinoma from 38 to 67 years of age with long life span, 60 (26\%)cases of different types of endometrial hyperplasia from 34 to 55 years of age, $48(21 \%)$ cases of uterovaginal prolapse from 45 to 68 years of age, 40 $(18 \%)$ cases of adenomyosis from 34 to 55 years of age and 8 (4\%) cases of 38 to 50 years of age.

Out of 226 hysterectomy cases, $70(30.97 \%)$ cases of different type of endometrial carcinoma were studied. The maximum $46(65.71 \%)$ cases were encountered in Endometroid secretory carcinoma, from 36-67 years of age (long life span), $16(22.90 \%)$ cases, of Endometroid adenosquamous carcinoma (adenoacanthoma and adenosquamous carcinoma) from 45-55 years of age, 3 $(4.30 \%)$ cases of Serous adenocarcinoma, $54-65$ years of age, $2(2.90 \%)$ cases of Clear cell carcinoma, 56-65 years of age and I $(1.42 \%)$ case each of other different types of endometrial cancer from 46-66 years of age were studied.

Table 1. Total numbers of different types of uterine diseases in hysterectomy specimens.

\begin{tabular}{lllll}
\hline Serial No. & Uterine diseases & No. of Cases & \% & 31.00 \\
\hline 1 & Endometrial carcinoma & 70 & $36-67$ \\
2 & Different types of endometrial hyperplasia & 60 & 26.00 \\
3 & Utero vaginal prolapse & 48 & 21.00 \\
4 & Adenomyosis & 40 & 18.00 & $45-55$ \\
5 & Uterine polyps & 08 & $34-00$ & 38 \\
6 & Total & 226 & 100 \\
\hline
\end{tabular}

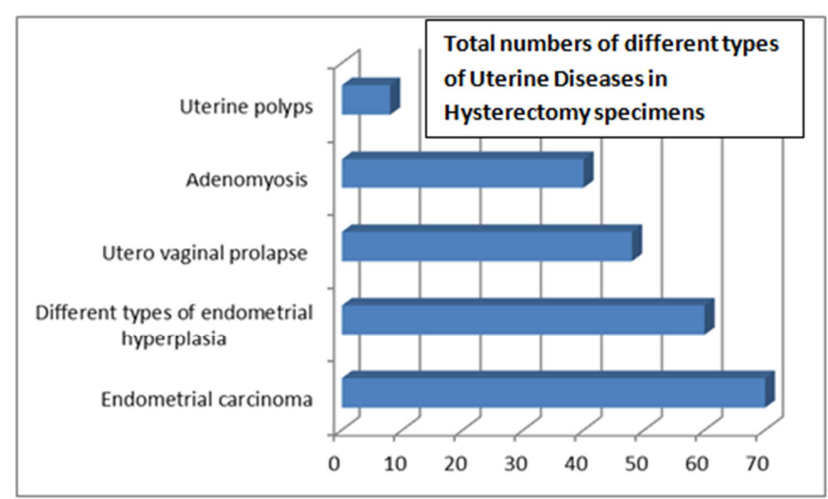

Graph 1. Total numbers of different types of uterine diseases in hysterectomy specimens.

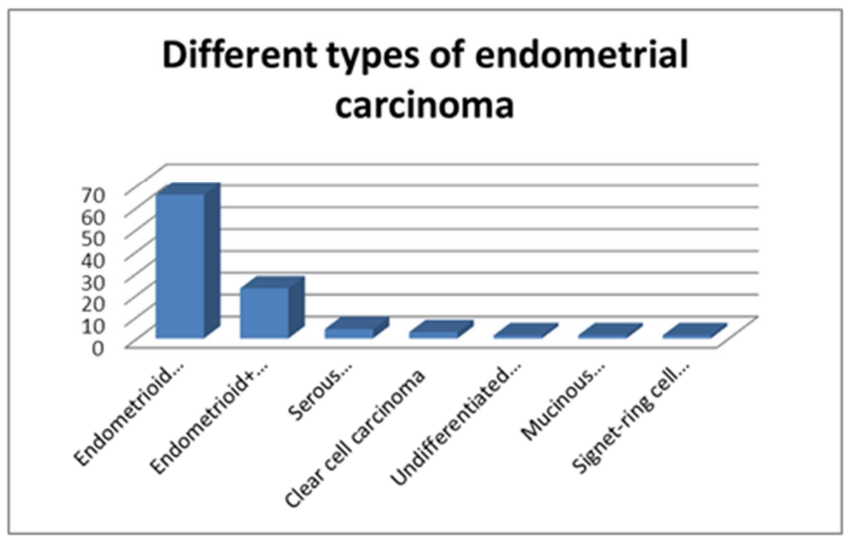

Graph 2. Different types of endometrial carcinoma. 
Table 2. Different types of endometrial carcinoma.

\begin{tabular}{|c|c|c|c|}
\hline S. No & Endometrial Cancer/Types & No. of cases & $\%$ \\
\hline 1 & Endometrioid adenocarcinoma & 46 & 65.71 \\
\hline 2 & $\begin{array}{l}\text { Endometrioid adenocarcinoma with } \\
\text { squamous cell differentiation }\end{array}$ & 16 & 22.90 \\
\hline 3 & Serous adenocarcinoma & 3 & 4.30 \\
\hline 4 & Clear cell carcinoma & 2 & 2.90 \\
\hline 5 & Undifferentiated carcinoma & 1 & 1.42 \\
\hline 6 & $\begin{array}{l}\text { Mucinous adenocarcinoma with } \\
\text { endometrioid carcinoma }\end{array}$ & 1 & 1.42 \\
\hline 7 & Signet-ring cell carcinomas & 1 & 1.42 \\
\hline 8 & Total & 70 & $100 \%$ \\
\hline
\end{tabular}

Table 3. Age groups of the patients having different types of endometrial carcinoma.

\begin{tabular}{lll}
\hline S. No & Endometrial carcinoma/Types & Age group / Years \\
\hline 1 & Endometroid adenocarcinoma & $36-67$ \\
2 & Endometroid adenocarcinoma with & $45-55$ \\
3 & squamous cell differentiation & $54-65$ \\
4 & Serous adenocarcinoma & $56-65$ \\
5 & Clear cell carcinoma & 66 \\
6 & Undifferentiated carcinoma & 47 \\
7 & Mucinous adenocarcinoma with & 46 \\
\hline
\end{tabular}

\section{Discussion}

The occurrence of endometrial cancer is $4-8 \%$ of all carcinoma, in many parts of the world.[17] It is the most common gynecological cancer [10] and the fourth leading cancer in the women in United States.[18] It is less common or lowest in rates in India and Southeast Asia. ${ }^{10}$ A study showed less than $1 \%$ endometrial carcinoma occurred, under 35 years and $6 \%$ occured in 45 years or less than 45 years of age.[19] Worldwide estimation of uterine cancer was done in 2002 of 199,000 cases showed 45,000 deaths per year with occurrence of $50 \%$ cases in developed countries.[2] The raised incidence of endometrial carcinoma in developing countries is found due to organized and improved socioeconomic conditions.[1] This can be occur by easy lifestyle, obesity and increase aging of population.[9] It is the tenth most common tumor occurring among women in China.[20] It is more common than other type of genital tract cancer in women. In United States 43,470 cases of endometrial carcinoma were detected in 2010.[21] It is also common in many other Western countries, mostly occurs between 55 to 65 years of age, and uncommon below 40 years of age.[16] It is difficult to describe the prevalence of endometrial cancer in South Asian/Indian subcontinent, where the breast and cervical cancers are common as compare to endometrial cancer. It is also difficult to describe the prevalence of endometrial cancer in sub-Sahara Africa, where histopathology services are very limited in more than 20 African countries.[22] In Pakistan there is increase tendency of endometrial cancers. A study showed earlier occurrence of endometrial carcinoma in Karachi, Pakistan, as the $15 \%$ of cancers occur in women younger than 40 years of age with a mean age of 53.7 years. It is nearly 10 years younger than that occurring in developed countries.[19]
In present study, total 226 hysterectomy cases of different type of diseases were studied with 70 cases of endometrial carcinoma. In the different types of endometrial carcinoma the maximum $46(65.71 \%)$ cases were encountered in Endometroid carcinoma, from 36-67 years of age with long life span, 16 (22.90\%) cases, of Endometroid adenosquamous carcinoma (adenoacanthoma and adenosquamous carcinoma) from 45-55 years of age, $3(4.30 \%)$ cases of Serous adenocarcinoma, 54-65 years of age, $2(2.90 \%)$ cases of Clear cell carcinoma, 56-65 years of age and in the remaining 3 cases or $1(1.42 \%)$ case each of other different types of endometrial cancer from 46-66 years of age were studied.

Endometroid carcinoma is appeared commonest in endometrial cancer from 38 to 55 years, as compare to other type of endometrial cancer. It is more common in postmenopausal women as reported in a study, the $75 \%$ occurrence of endometrial cancer in postmenopausal women and, only $3-10 \%$ occurrence in less than 40 years of age.[10] Most common endometrial carcinoma is adenocarcinoma 61$71 \%$, adenosqamous carcinoma and adenoacanthoma is $14-$ $24 \%$ and rest are papillary serous tumor \& clear cell carcinoma.[23] Uterine Clear cell carcinoma, is rare and about $1-6 \%$ in occurrence. Histologically it appears with clear cytoplasm in tumor cells.[24]

\section{Conclusion}

In the present study there are $70(31 \%)$ cases of endometrial carcinoma. The maximum $46(65.71 \%)$ cases were encountered in Endometroid secretory carcinoma, 3667 years of age and $16(22.90 \%)$ cases, of Endometroid adenosquamous carcinoma (adenoacanthoma and adenosquamous carcinoma), 45-55 years of age. In the types of endometrial carcinoma, there was increased tendency of Endometroid adenocarcinoma with long life span (36-67 years), as compare to other developed countries where it is also commonly occurring tumor. Comparing with all research on this histologic type of endometrial carcinoma, our data is limited by small sample size. However, these results may help to guide future prospective research from which we draw more concrete conclusions regarding early diagnosis treatment and follow up of the patients.

\section{References}

[1] Bhurgri Y, Nazir K, Shaheen Y, et al. Pathoepidemiology of cancer corpus uteri in Karachi South "1995-1997" Asian Pac J Cancer Prev. 2007;8:489-494.

[2] Pecorelli S, Favalli G, Zigliani L, Odicino F. Cancer in women. Int J Gynaecol Obstet. 2003;82:369-379.

[3] Kurman RJ, Kamiriski PF, Norris HJ. The behavior of endometrial hyperplasia; A long term study of untreated endometrial hyperplasia in 170 patients. Cancer 1985;56:40312.

[4] Richard Cote, Saul Suster, Lawrence Weiss, Noel Weidner (Editor) (2002). Modern Surgical Pathology (2 Volume Set). London: W B Saunders. 
[5] Kurman RJ, Kaminski PF, Norris HJ (1985). "The behavior of endometrial hyperplasia. A long-term study of "untreated" hyperplasia in 170 patients". Cancer 56 (2): pp.403-12.

[6] Friedenreich, CM; Neilson, HK, Lynch, BM (2010 Sep). "State of the epidemiological evidence on physical activity and cancer prevention.". European journal of cancer (Oxford, England: $\quad 1990) \quad 46 \quad$ (14):2593 604. doi:10.1016/j.ejca.2010.07.028.

[7] Yamazawa, K; Shimada, H; Hirai, M; Hirashiki, K; Ochiai, T; Ishikura, H; Shozu, M; Isaka, K (2007). "Serum p53 antibody as a diagnostic marker of high-risk endoametrial cancer.". American journal of obstetrics and gynecology 197 (5):05.e17.doi:10.1016/j.ajog.2007.04.033.

[8] Reeler A, Qiao Y, Dare L, et al. Women's cancers in developing countries: from research to an integrated health systems approach. Asian Pac J Cancer Prev. 2009;10:519526.

[9] Salazar-Martínez E, Lazcano-Ponce EC, Lira-Lira GG, et al. Case-control study of diabetes, obesity, physical activity and risk of endometrial cancer among Mexican women. Cancer Causes Control. 2000;11:707-711.

[10] Creasman WT. Endometrial Carcinoma. eMedicine Specialities> Obstetrics and Gynaecology> Gyncologic Oncology. Updated July 2007.

[11] Tavassoli F, Devilee P. World Health Organization Classification of Tumours. Pathology and Genetics of Tumours of the Breast and Female Genital Organs. Lyon: IARC Press, 2003.

[12] Richard Cote, Saul Suster, Lawrence Weiss, Noel Weidner (Editor) (2002). Modern Surgical Pathology (2 Volume Set). London: W B Saunders.

[13] Anderson MC, Robboy SJ, Russell P, Morse A: Endometrial carcinoma. In Pathology of the female reproductive tract. Edited by Robboy SJ, Anderson MC, Russell P. London, Churchill Livingston; 2002:331-359.
[14] Lax SF, Pizer ES, Ronnett BM, Kurman RJ: Comparison of estrogen and progesterone receptor, $\mathrm{Ki}-67$, and p53 immunoreactivity in uterine endometrioid carcinoma and endometrioid carcinoma with squamous, mucinous, secretory, and ciliated cell differentiation.Hum athol 1998, 29:924-931.

[15] Berek JS, Hacker NF, eds. Practical gynecologic oncology. 2d ed. Baltimore: Williams \& Wilkins, 1994:285-326.

[16] DiCristofano A, Ellenson LH: Endometrial carcinoma. Annual Review of Pathology: Mechanisms of Disease, Vol. 2:57, 2007. [A comprehensive discussion of pathogenesis.]

[17] Jemal A, tiwari RC, Murray T, Ghafoor A, Ward E, Thun MJ. Cancer statistics, 2004. CA Cancer J Clin 2004; 54: 8-29.

[18] Walsh C, Holschneider C, Hoang Y et al. Co-existing ovarian malgnancy in young women with endometrial cancer. Obstetrics and Gynaecology 2005; 106: 693-9.

[19] Mackenzie I.Z, Bibby J,G. "Critical assessment of dilatation and curettage on 1029 women". Lancet 1978; 566-9.

[20] Wernli KJ, Ray RM, Gao DL, et al. Occupational risk factors for endometrial cancer among textile workers in Shanghai, China. Am J Ind Med. 2008;51:673-679.

[21] A. Jemal, R. Siegel, J. Xu, and E. Ward, "Cancer statistics, 2010,” CA: A Cancer Journal for Clinicians, vol. 60, no. 5, pp. 277-300, 2010.

[22] Parkin DM, Whelan SL, Ferlay J, et al., editors. Cancer Incidence in Five Continents. Vol. VIII. Geneva: World Health Organization; 2007. (International Agency for Research on Cancer Publication No. 155).

[23] Leuw WJ, Dierssen J, Varen HF et al. Prediction of a mismatch repair gene defect by micro satellite instability and immunohistochemical analysis in endometrial - from HNPCE patients J Pathal 2000, 192-328.

[24] T. P. Boren and D. S. Miller, "Should all patients with serous and clear cell endometrial carcinoma receive adjuvant chemotherapy?" Women's Health, vol. 6, no. 6, pp. 789-795, 2010 . 